\title{
Comparative studies of social behavior in Callicebus and Saimiri: Social looking in male-female pairs
}

\author{
MICHAEL J. PHILLIPS and WILLIAM A. MASON \\ University of California, Davis, California 95616
}

\begin{abstract}
Duration of looking at a cagemate was investigated in two primate species, one (Callicebus), which in nature forms pair bonds, and the other (Saimir), which does not. Five male-female pairs of each species were observed in their living cages. Callicebus spent significantly more time in both mutual and unilateral looking at cagemates than did Saimiri.
\end{abstract}

Field and laboratory data indicate that the titi monkey (Callicebus) is disposed to form a strong and specific attachment to a member of the opposite sex (Mason, 1966, 1975). In contrast, the squirrel monkey (Saimiri) shows little if any tendency to develop specific heterosexual pair bonds (Mason, 1971, 1975). This report presents additional information on the social relationship within male-female pairs of these two South American species.

Inasmuch as sustained visual regard appears to be a significant aspect of primate social attraction (Mitchell, 1972), it was anticipated that such behavior would be more prominent in a pair-bonding species. To test this possibility, amount of looking directed at the cagemate was compared in heterosexual pairs of Saimiri and Callicebus.

\section{METHOD}

\section{Subjects and Living Arrangements}

Five adult heterosexual pairs from each species served as subjects. At the start of observations, the titi monkeys (Callicebus moloch) had lived in captivity for at least 4 years and with the same cagemate for at least 1 year; the squirrel monkeys (Saimiri) had lived in captivity for at least 1 year and with the same cagemates for at least 8 months. All pairs were housed in similar indoor-outdoor cages. The indoor compartment (approximately $1 \times 1 \times 3 \mathrm{~m}$ ) was separated from the outdoor compartment by a sliding door $(30 \times 20 \mathrm{~cm})$ that was closed during observations. The outdoor compartment, in which the pairs were observed, was approximately $2 \mathrm{~m}$ high, $1 \mathrm{~m}$ wide, and $4 \mathrm{~m}$ long and was equipped with two rectangular perch frames $(1 \times .5 \mathrm{~m}), 1.0 \mathrm{~m}$ and $1.3 \mathrm{~m}$ from ground level. Ceilings of the outdoor compartments were partly shaded by netting and partial visual isolation between adjacent compartments was accomplished by transluscent plastic screening, through which indistinct shapes and movement could be

This research was supported by Grants GB-8202 from the National Science Foundation and RR-00169 from the National Institutes of Health, US Public Health Service. We gratefully acknowledge the assistance of Kristy A. Phillips in this research. Address requests for reprints to W. A. Mason, Department of Psychology, University of California, Davis, California 95616. discerned. Food and water were available ad lib in the indoor compartment.

\section{Apparatus and Procedure}

Approximately $15 \mathrm{~min}$ before the start of a day's observations, all monkeys were locked within the outdoor compartments. The observer sat about $.5 \mathrm{~m}$ from the front of the cage containing the subject pair and began the 5-min observation period by starting a 15-sec interval counter. The following behavior categories were scored: (1) Visual orientation. Scored to the nearest $.1 \mathrm{sec}$ by an electronic timer whenever a line perpendicular to the frontal plane of the face of either monkey intersected the partner. Separate timers were used to record durations of male orientation to female, female orientation to male, and mutual (concurrent) orientation. (2) Social proximity. Approximately $30 \mathrm{~cm}$ or less separating cagemates. (3) Social contact. Any touching of body surfaces between cagemates. (4) Social grooming. Combing through cagemate's fur with the hands. Proximity, contact, and grooming were scored by 15 -sec intervals and no category was scored more than once in an interval.

Each pair was observed for 105 -min sessions, each session on a different day. All pairs were observed once on an observation day, and observations were made 2 or 3 days a week. Insofar as possible, time of day and the order in which species and pairs within species were observed was balanced.

Reliability, established by having two observers score 10 sessions independently, was .99 for all behavior categories (product-moment correlations). Statistical comparisons are based on t tests and two-tailed probabilities were used throughout.

\section{RESULTS AND DISCUSSION}

The results indicate that titi monkeys housed in heterosexual pairs spent substantially more time looking at each other than did equivalent pairs of squirrel monkeys. Figure 1a presents mean pair totals for duration of unilateral looking per session. The value for titi monkeys $(38.0 \mathrm{sec})$ is significantly different from that for squirrel monkeys $(21.3 \mathrm{sec}, \mathrm{p}<.02)$. As in previous research comparing these species (Mason, 1974), titi monkeys engaged in significantly more social grooming than did squirrel monkeys. In fact, in this research no squirrel monkey was observed to groom, whereas every titi monkey did so on at least five $15-\mathrm{sec}$ intervals (mean total $=19.1)$. Because a positive corre- 

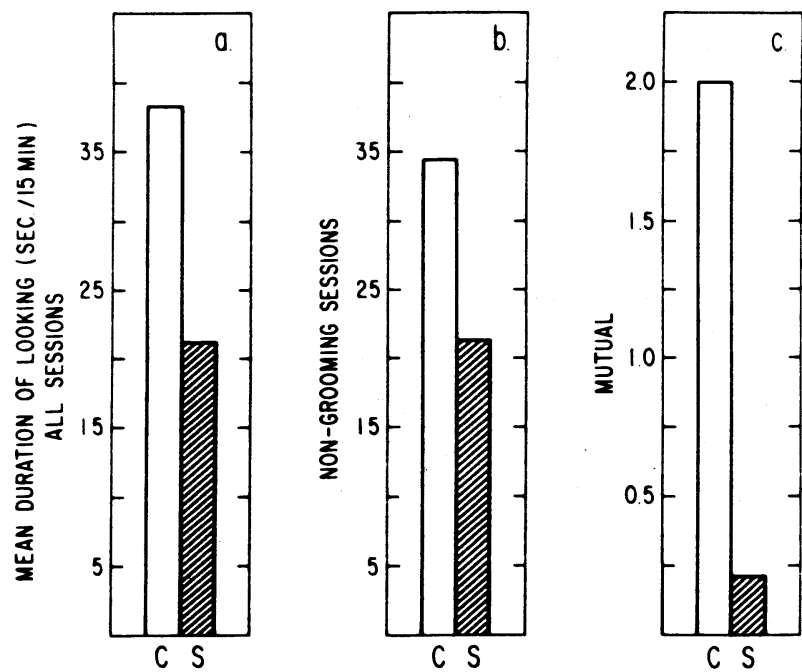

Figure 1. Duration of visual orientation toward cagemate by titi monkeys (C) and squirrel monkeys (S). Figure 1a: Mean pair totals for duration of unilateral looking per $5 \mathrm{~min}$, based on all observation sessions. Figure 1b: Mean pair totals for duration of unilateral looking per $5 \mathrm{~min}$, excluding sessions in which a subject groomed its cagemate. Figure 1c: Mean duration of mutual (concurrent) looking per 5 min, based on all observation sessions.

lation can be expected between grooming and visual orientation, a separate analysis of looking behavior was made in which all of a monkey's sessions in which it groomed its mate were excluded. Interspecies differences remained substantial and significant (Figure $1 \mathrm{~b}$, mean pair totals $/ 5 \mathrm{~min}$ : titis, $34.5 \mathrm{sec}$ vs. squirrel monkeys, $21.3 \mathrm{sec}, \mathrm{p}<.05)$. The amount of mutual looking also differentiated species. Although mean durations were small, titi monkeys spent much more time in mutual looking than did squirrel monkeys (Figure $1 \mathrm{c}, \mathrm{p}<.01$ ) and showed this behavior much more frequently (74\% of sessions vs. $26 \%$ of sessions, $\mathrm{p}<.01$ ).

Separate analyses of looking behavior by sexes indicated larger interspecies differences between females than between males. Female titi monkeys had significantly larger duration scores than female squirrel monkeys on both grooming and nongrooming trials $(\mathrm{p}<.02)$, whereas differences between males on these measures, although in the same direction as for females, were not statistically significant. Female titis also spent significantly more time looking at their mates than did male titi monkeys, but only on "nongrooming" trials $(\mathrm{p}<.05)$. Sex differences were not significant on any measure of looking behavior for squirrel monkeys.

Measures of social contact were considerably higher for titis than for squirrel monkeys $(46.5 \%$ vs. $28.8 \%)$, as were measures of proximity $(60.6 \%$ vs. $42.1 \%)$, although interspecies differences were not statistically significant.

The finding that male-female pairs of titi monkeys spent significantly more time in both mutual and unilateral looking than comparable pairs of squirrel monkeys extends the general description of the pair bond in titi monkeys, based on other measures and situations, and provides further evidence of the contrasting relations between the sexes in the two species. The fact that female titis looked at their mates more than their mates looked at them is also in keeping with previous results suggesting that attachment is somewhat stronger in the female (Mason, 1971).

Our results offer no direct evidence concerning the functional significance of contrasts between titis and squirrel monkeys in social looking behavior; however, it is reasonable to suppose that the higher level of visual orientation in titi monkeys is part of the general process of "keeping in touch" which results in the marked cohesiveness and coordination shown by established social groups of this species (Mason, 1966, 1968, 1974).

\section{REFERENCES}

Mason. W. A. Social organization of the South American monkey, Callicebus moloch: A preliminary report. Tulane Studies in Zoologv. 1966, 13, 23-28.

Mason, W. A. Use of space by Callicebus groups. In P. C. Jay (Ed.), Primates: Studies in adaptation and variability. New York: Holt. Rinehart, \& Winston, 1968. Pp. 200-216.

MAson. W. A. Field and laboratory studies of social organization in Saimiri and Callicebus. In L. A. Rosenblum (Ed.), Primate behavior: Developments in field and laboratory research (Vol. 2). New York: Academic Press, 1971. Pp. 107-137.

Mason, W. A. Comparative studies of social behavior in Callicebus and Saimiri: Behavior of male-female pairs. Folia Primatologica, 1974, 22 . 1-8.

Mason, W. A. Comparative studies of social behavior in Callicebus and Saimiri: Strength and specificity of attraction between male-female cagemates. Folia Primatologica, 1975. 23. 113-123.

Mitchell. G. Looking behavior in the rhesus monkey. Journal of Phenomenological Psychology, 1972. 3. 53-67.

(Received for publication September 19. 1975.) 